\title{
Survival among patients admitted in PICU (Pediatric Intensive Care Unit) of tertiary childcare hospital.
}

\footnotetext{
1. MBBS

Post Graduate Resident Pediatric Medicine

The Children's Hospital \& ICH, Multan.

2. MBBS, FCPS (Paediatric Medicine) Associate Professor Paediatric Medicine

The Children's Hospital \& ICH, Multan.

3. MBBS, FCPS (Pediatric Medicine) Assistant Professor Paediatric Medicine

Nishtar Medical University and Hospital, Multan
}

Correspondence Address:

Dr. Asim Khurshid

Department of Pediatric Medicine

The Children's Hospital \& ICH.

asimkhurshiddr@gmail.com

Article received on:

$15 / 08 / 2020$

Accepted for publication:

$12 / 02 / 2021$

\begin{abstract}
Fatima Jabeen ${ }^{1}$, Asim Khurshid ${ }^{2}$, Maria Saleem ${ }^{3}$
\end{abstract}
ABSTRACT... Objective: To determine the frequency of survival among patients admitted in Paediatric Intensive Care Unit (PICU) of tertiary care hospital according to disease severity score PRISM III. Study Design: Descriptive study. Setting: PICU of The Children's Hospital and Institute of Child Health, Multan. Period: October 2019 to April 2020. Material \& Methods: A total of 205 admitted children in PICU were recruited. PRISM III forms were filled and PRISM III score was calculated for all study participants. Results: Of these 205 study cases, 124 (60.5\%) were male patients while 81 (39.5\%) were female patients. Mean age of our study cases was $3.64 \pm 1.96$ years. Mean duration of PICU stay was $4.52 \pm 3.59$ days and 139 (67.8\%) patients had PICU stay for upto 5 days. Mean PRISM III score was $11.25 \pm 4.69$ and 69 (33.7\%) had group I score, $118(57.6 \%)$ had group II score, $14(6.8 \%)$ had group III score and $4(2 \%)$ had group IV score. Of these 205 study cases, mortality was noted in 31 (15.1\%). Conclusion: High Frequency of mortality among children admitted to pediatric intensive care unit (PICU) was observed and mortality was found to be increasing with increasing PRISM III score.

Key words: $\quad$ Mortality, PRISM III, Pediatric Intensive Care Unit.

Article Citation: Jabeen F, Khurshid A, Saleem M. Survival among patients admitted in PICU (Pediatric Intensive Care Unit) of tertiary childcare hospital. Professional Med J 2021; 28(12):1773-1777. https://doi.org/10.29309/TPMJ/2021.28.12.5991

\section{INTRODUCTION}

Among developing country, childhood mortality is quite high. In 2010, "United Nations" calculated infant mortality rate (IMR) ranging 1.92 in Singapore to 135 in Afghanistan and 53.9 per 1000 live-births in Pakistan. ${ }^{1}$ In the last few decades, improvement in paediatric intensive care has led to decrease in childhood mortality especially in the developed countries. ${ }^{2}$ Handling of critically ill children with the help of well-equipped paediatric intensive care unit (PICU) have given a huge advantage in advancement to desired outcomes. ${ }^{3}$

It is vitally important to estimate the risk of mortality in different settings which can hugely help in calculating prognosis, resource utilization and effectiveness of treatment regimens. ${ }^{4}$ Various scoring systems are in place and used for these purposes in the PICUs. Paediatric risk of mortality (PRISM III) is one of the most popular scoring systems adopted for prediction of death in children admitted to PICUs. ${ }^{5,6}$ As the scores of PRISM III increase as does the chances of mortality. If mortality rates are high at low PRIMS III scores, the efficiency of a PICU is taken as less efficient. Depending upon facilities different PICU have different mortality rate ranging from $7 \%$ to $25.9 \%{ }^{5,7}$ In a study done at Agha Khan Hospital Karachi shows overall mortality up to $14 \% .{ }^{8}$ A study done by Khurshid et al here in PICU, Multan shows overall mortality of $19.1 \% .^{9}$

Rady et al studied that mean PRISM III was raised among non-survivors when compared to survivors $(12.9 \pm 9.2$ vs. $5.7 \pm 4.8) .{ }^{10}$ In a study done by Bellad et al, mean PRISM scores were $6.5+/ 3.6$ for survivors and $15.5+/-7$ for nonsurvivors. ${ }^{11}$ Das et al studied if PRSIM score is $1-9$ then mortality is up to $2 \%$, if score is $11-19$ then mortality is up to $8 \%$, if score is more than 20 then mortality is up to $100 \% .{ }^{12}$ Khurshid et al here in PICU, Multan found that mean PRISM III score was $13.2(4-36) .^{9}$

In a previous study done in PICU of our tertiary care hospital PRISM III score was calculated but it 
was not compared in survivors and non-survivors. This study may be helpful in determining the outcome of the patients admitted in PICU of a tertiary childcare hospital in relation with Disease severity score PRISM III within 24 hours and it will be assessed that what is the PRISM III score in survivors and non-survivors so that we can assess our PICU weather it is functioning in pace with good PICU or not and needs some improvement.

\section{MATERIAL \& METHODS}

This descriptive study was done at PICU of The Children's Hospital and Institute of Child Health, Multan from 25-10-209 to 24-04-2020. Approval from institute's ethics committee was taken for this study. Approval from parents/guardians of all the study participants was also acquired.

A sample size of 205 was calculated considering mortality rate of PICU as $7 \%$ by Rady et $\mathrm{al}^{5}$, margin of error $3.5 \%$ and confidence level $95 \%$. A total of 205 children of both genders, admitted in PICU, aged between 1 month to 12 years were enrolled. Children who died within $1^{\text {st }} 24$ hours, or those with congenital malformations like congenital heart disease (labeled on clinical examination and appropriate investigations), who were discharged from the unit within 24 hours of admission or those with malignancies were excluded (on clinical examination and appropriate investigations).

PRISM III form was filled and score calculated for each study participant which is a disease severity score. All this information was collected and recorded on a predefined Performa. Pediatric risk of mortality-III (PRISM III) is a disease severity score for pediatric age group. A patient who is successfully treated and discharged or shifted from PICU to some other ward in satisfactory condition (vitally stable) for residual improvement was labeled as survivor. Non-Survivor was labeled as a patient who expired during the stay in PICU within 2 weeks of admission.

All the collected data was analyzed through SPSS version 26.0. For each group quantitative variables like age, Length of stay (LOS) and PRISM III score was presented as mean and standard deviation. For each group qualitative variables like gender and outcome variable survival or non-survival were presented in frequency and percentage. Effect modifier like age, gender, PICU duration and PRISM III score were dealt through stratification. Post stratification chi square was applied. P-value $\leq 0.05$ was taken as significant.

\section{RESULTS}

Out of 205 study cases, 124 (60.5\%) were male and 81 (39.5\%) female. Overall, mean age was $3.64 \pm 1.96$ years (ranging 1 to 8 years). Majority of the cases, 172 (83.9\%) were aged less than or equal to 5 years. There were $104(50.7 \%)$ children who belonged to rural areas while 150 (73.2\%) were having middle income socioeconomic status. Of these 205 study cases, 140 (68.3\%) mothers were illiterate. Mean duration of PICU stay was $4.52 \pm 3.59$ days and 139 (67.8\%) patients had PICU stay $<5$ days. Mean PRISM III score was $11.25 \pm 4.69$ and 69 (33.7\%) had group I score, 118 (57.6\%) had group II score, 14 (6.8\%) had group III score and 4 (2\%) had group IV score (Table-I).

\begin{tabular}{|c|c|c|}
\hline \multicolumn{2}{|c|}{ Characteristics } & Number (\%) \\
\hline \multirow{2}{*}{ Gender } & Male & $124(60.5 \%)$ \\
\hline & Female & 81 (39.5\%) \\
\hline \multirow{2}{*}{$\begin{array}{l}\text { Age Groups } \\
\text { (years) }\end{array}$} & $<5$ & 172 (83.9\%) \\
\hline & $>5$ & $33(16.1 \%)$ \\
\hline \multirow{2}{*}{$\begin{array}{l}\text { Residential } \\
\text { Status }\end{array}$} & Rural & $104(50.7 \%)$ \\
\hline & Urban & 101 (49.3\%) \\
\hline \multirow{3}{*}{$\begin{array}{l}\text { Socioeconomic } \\
\text { Status }\end{array}$} & Poor & $55(26.8 \%)$ \\
\hline & Middle & $138(67.3 \%)$ \\
\hline & High & $12(5.6 \%)$ \\
\hline \multirow{2}{*}{ Maternal Literacy } & Illiterate & $140(68.3 \%)$ \\
\hline & Literate & 65 (31.7\%) \\
\hline \multirow{2}{*}{$\begin{array}{l}\text { Duration of PICU } \\
\text { Stay (days) }\end{array}$} & $<5$ & 139 (67.8\%) \\
\hline & $>5$ & $66(32.2 \%)$ \\
\hline \multirow{4}{*}{$\begin{array}{l}\text { PRISM III } \\
\text { (Grade) }\end{array}$} & 1 & $69(33.7 \%)$ \\
\hline & II & 118 (57.6\%) \\
\hline & III & $14(6.8 \%)$ \\
\hline & IV & $4(2.0 \%)$ \\
\hline
\end{tabular}

Of these 205 study cases, mortality was noted in $31(15.1 \%)$ children as shown in Figure-1. 


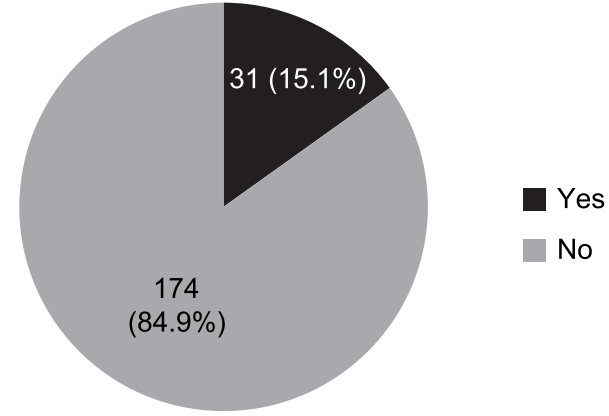

Figure-1. Mortality among study cases.

Table-Il shows stratification with regards to gender, age, residential status, socioeconomic status, maternal literacy, duration of PICU stay and PRISM III score. A significant association of mortality with male gender, aged less than 5 years, low socioeconomic status, duration of PICU stay less than 5 days and high PRISM III score was noted.

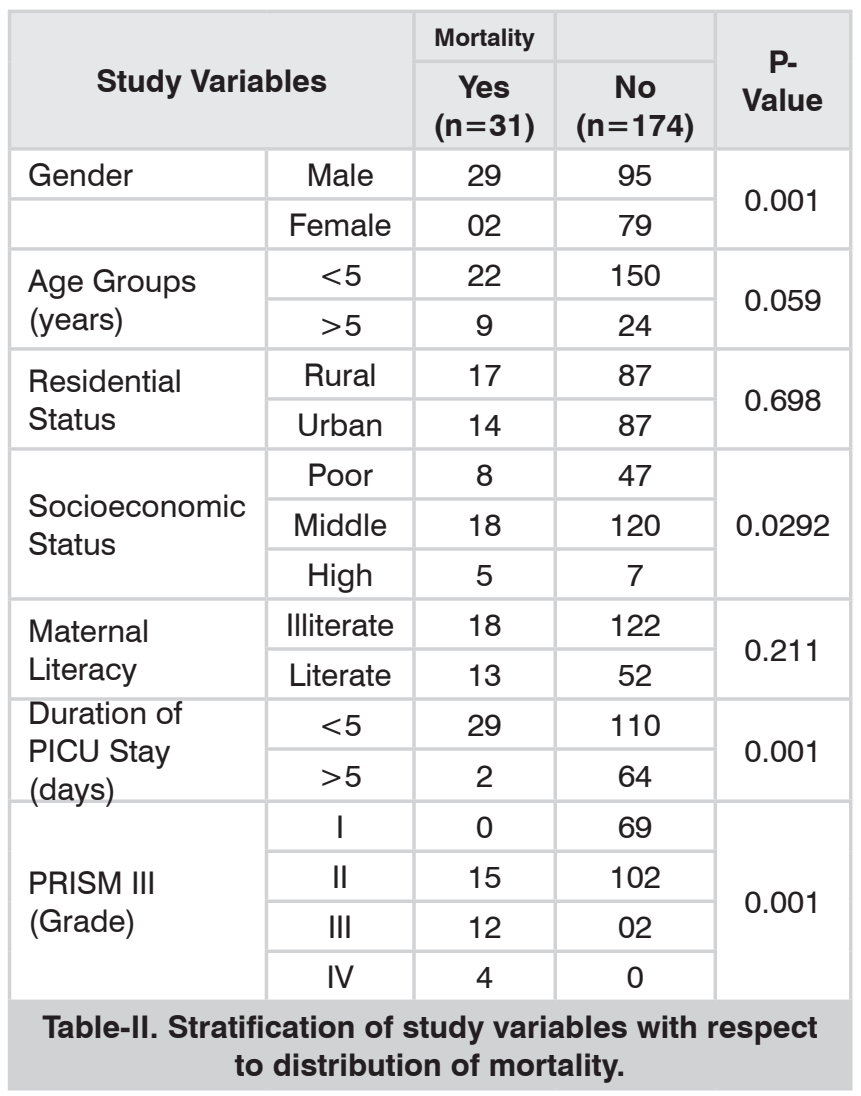

\section{DISCUSSION}

In this study, most children, 124 (60.5\%) were male. Haque et al in a local study found $66.5 \%$ of their study participants admitted in the PICU to be male. ${ }^{13}$ Another research from Karachi also recorded male prevalence to be $66.0 \%$ in terms of admission in the PICU. ${ }^{14}$ Rady HI from Egypt also reported $56 \%$ male gender predominance. ${ }^{15}$ Mean age of our study cases was $3.64 \pm 1.96$ years. Haque et al also reported $56.3 \pm 5.5$ months mean age of the children admitted to PICU. ${ }^{13}$ Another local data reported $63.0 \%$ children admitted to PICU were less than 5 years. ${ }^{14}$ Ahmed et al also found mean age of the children admitted to PICU which is in compliance to the current findings. ${ }^{16}$ Volakali et al and Abebe et al also reported similar findings. ${ }^{17,18}$

Of these 205 study cases, 104 (50.7\%) belonged to rural areas and 101 (49.3\%) belonged to urban areas. Poor socioeconomic status was noted in 55 (26.8\%) and 150 (73.2\%) were middle income. Of these 205 study cases, 140 (68.3\%) mothers were illiterate while $65(31.7 \%)$ mothers were literate. A study conducted by Ramzan et al 89 reported $28 \%$ poverty rate and $40.7 \%$ were illiterate. ${ }^{19}$

Mean duration of PICU stay was $4.52 \pm 3.59$ days and 139 (67.8\%) patients had PICU stay for up to 5 days. Ahmed et al noted mean stay at PICU from admitted children to be 3.9 days which to close to what we noted. ${ }^{16}$ In comparison to our findings, Volakali and colleagues found an extended duration of stay (8.85 \pm 23.28 days). ${ }^{17}$ Ramzan et al 89 also reported similar results. ${ }^{19}$

Mean PRISM III score was $11.25 \pm 4.69$ and 69 (33.7\%) had group I score, 118 (57.6\%) had group II score, 14 (6.8\%) had group III score and 4 (2\%) had group IV score. Of these 205 study cases, mortality was noted in 31 (15.1\%). In a study done at Agha Khan Hospital Karachi shows overall mortality up to $14 \% .{ }^{8}$ A study done by Khurshid et al here in PICU, Multan shows overall mortality of $19.07 \% .^{9}$ Rady et al studied that mean PRISM III was high among non-survivors when compared to survivors $(12.9 \pm 9.2$ vs. $5.7 \pm 4.8) .{ }^{5}$ Bellad et al noted that the mean PRISM score was $6.5+3.6$ and $15.5+7$ for survivors and non survivors, respectively. ${ }^{11}$ Das et al studied if PRSIM score 
is $1-9$ then mortality is up to $2 \%$, if score is $11-19$ then mortality is up to $8 \%$, if score is more than 20 then mortality is up to $100 \% .^{12}$

Our study had few limitations as well. As this was a single center study, the results of our findings cannot be generalized. We also could not evaluate the impact of individual comorbid conditions on the enrolled child. No data regarding management options in the included children highlighted in the present study.

\section{CONCLUSION}

High Frequency of mortality among children admitted to PICU was observed and mortality was found to be increasing with increasing PRISM III score. Hence PRISM III scoring can be employed in PICU as prognostic scoring system to anticipate outcomes and to improve management services for these patients which will decrease further adverse events in these patients. Mortality was significantly associated with gender, age, prolonged duration of PICU stay and PRISM III scoring.

Copyright@ 12 Feb, 2021.

\section{REFERENCES}

1. Shukla VV, Nimbalkar SM, Phatak AG, Ganjiwale JD. Critical analysis of PIM2 score applicability in a tertiary care PICU in western India. Int J Pediatr. 2014; 2014:703942.

2. Knoester H, Martha A, Albert P. Outcome of paediatric intensive care survivors. Eur J Pediatr. 2007 Nov; 166(11):1119-28.

3. Abhulimhen-lyoha1 BI, Pooboni SK, Kumar Vuppali NK. Morbidity pattern and outcome of patients admitted into a pediatric intensive care unit in India. Indian $\mathrm{J}$ Clin Med. 2014; 5:1-5.

4. Mirza S, Malik L, Ahmed J, Malik F, Sadiq h, Ali S, et al. Accuracy of Pediatric Risk of Mortality (PRISM) III Score in Predicting Mortality Outcomes in a Pediatric Intensive Care Unit in Karachi. Cureus 2020; 12(3):e7489.

5. Rady HI, Mohamed SA, Mohssen NA, Elbaz M. Application of different scoring systems and their value in pediatric intensive care unit. Gaz Egypt Paediatr Assoc. 2014 Dec; 62(4):59-64.
6. Rady HI. Profile of patients admitted to pediatric intensive care unit, Cairo University Hospital: 1-year study. Ain-Shams J Anaesthesiol 2014; 7:500-3.

7. Roshani N. TaoriKeya R. Milind S. Performance of PRISM (Pediatric Risk of Mortality) score and PIM (Pediatric Index of Mortality) score in a tertiary care pediatric ICU. Indian J Peds. 2010 Mar; 77(3):267-71.

8. Haque A, Bano S. Clinical profile and outcome in a paediatric intensive care unit in Pakistan. J Coll Physicians Surg. 2009; 19(8):534-5.

9. Khurshid A, Khan A, Saleem M, Zafar F. Clinical profile and outcome in a paediatric intensive care unit in Pakistan. Pak J Med Health Sci. 2015; 9(2):623-5.

10. Rady HI, Mohamed SA, Mohssen NA, Elbaz M. Application of different scoring systems and their value in pediatric intensive care unit. Gaz Egypt Paediatr Assoc. 2014 Dec; 62(4):59-64.

11. Bellad R, Rao S, Patil VD, Mahantshetti NS. Outcome of intensive care unit patients using Pediatric Risk of Mortality (PRISM) score. Indian Pediatr. 2009; 46(12):1091-2.

12. Das KK, Kumar A, Paul P, Aggarwal KC. Application of pediatric risk of mortality-III score to predict outcome in critically sick children admitted in a tertiary care pediatric unit in a developing country. Indian $\mathrm{J}$ Child Health. 2016; 3(2):93-7.

13. Haque A, Saleem AF. On admission hypomagnesemia in critically ill children: Risk factors and outcome. Indian J Pediatr. 2009; 76(12):1227-30.

14. Haque A, Siddiqui NR, Jafri SK, Hoda M, Bano S, Mian A. Clinical profiles and outcomes of children admitted to the pediatric intensive care unit from the emergency department. J Coll Physicians Surg Pak 2015; 25(4):301-3.

15. Rady HI. Profile of patients admitted to pediatric intensive care unit, Cairo University Hospital: 1-year study. Ains Sham J Anaesthesiol. 2014; 7(4):500-3.

16. Ahmed K, Jafr SK, Bhatti F, Rafique A, Haque A. Clinical profile and outcome of children admitted with status epileptics in PICU of a developing country. Pak J Neurological Sci. 2013; 8(2):1-6.

17. Volakli E, Sdougka M, Tamiolaki M, Tsonidis C, Reizoglou M, Giala M. Demographic profile and outcome analysis of pediatric intensive care patients. Hippokratia. 2011; 15(4): 316-22. 
18. Abebe T, Girmay M, Michael G, Tesfaye M. The epidemiological profile of pediatric patients admitted to the general intensive care unit in an Ethiopian university hospital. Int J Gen Med. 2015; 8:63-7.
19. Ramzan S, Zaffar J, Mazhar S. Hyponatremia among critically ill children admitted to pediatric intensive care unit (PICU). J Med Physiol Biophys. 2017; 37:3539.

\begin{tabular}{|c|c|c|c|}
\hline \multicolumn{4}{|c|}{ AUTHORSHIP AND CONTRIBUTION DECLARATION } \\
\hline No. & Author(s) Full Name & Contribution to the paper & Author(s) Signature \\
\hline 1 & Fatima Jabeen & Data collection, Data & 2 \\
\hline 2 & & $\begin{array}{l}\text { Study concept, Drafting } \\
\text { Supervision, Proof reading. }\end{array}$ & $\stackrel{8}{=}$ \\
\hline 3 & Maria Saleem & $\begin{array}{l}\text { Methodology, Literature } \\
\text { review, Discussion. }\end{array}$ & $\mathbb{Q}$ \\
\hline
\end{tabular}

